\title{
The evolution of brain size among the Homininae and selection at ASPM and MCPH1 genes
}

\author{
Sandra Leyva-Hernández ${ }^{\mathrm{a}, \mathrm{b}}$, Ricardo Fong-Zazueta ${ }^{\mathrm{a}, \mathrm{d}}$, Luis Medrano-González (ORCID 0000-0002- \\ 8217-5095) ${ }^{c}$ and Ana Julia Aguirre-Samudio (ORCID 0000-0002-6674-5641) d* $^{*}$
}

${ }^{a}$ Escuela Nacional de Antropología e Historia, Ciudad de México, México; ${ }^{b}$ Procuraduría General de Justicia del Estado de Guanajuato, Guanajuato, México; 'Facultad de Ciencias, Universidad Nacional Autónoma de México, Ciudad de México, México; 'Laboratorio de Antropología Genética. Instituto de Investigaciones Antropológicas, Universidad Nacional Autónoma de México, Ciudad de México, México

*Corresponding author: Aguirre Samudio A.J. Laboratorio de Antropología Genética, Instituto de Investigaciones Antropológicas, Universidad Nacional Autónoma de México. Phone: +52 5556229685 ; e-mail:ajua@unam.mx

(C) The Authors, 2021

\begin{abstract}
We examined the evolutionary relationship of the ASPM (abnormal spindle-like microcephaly associated) and $M C P H I$ (microcephalin-1) genes with brain volume among humans and other primates. We obtained sequences of these genes from 14 simiiform species including hominins. Two phylogenetic analyses of $A S P M$ exon 3 and $M C P H 1$ exons 8 and 11 were performed to maximize taxon sampling or sequence extension to compare the nucleotide substitution and encephalization rates, and examine signals of selection. Further assessment of selection among humans was done through the analysis of non-synonymous and synonymous substitutions $\left(\mathrm{d}_{\mathrm{N}} / \mathrm{d}_{\mathrm{S}}\right)$, and linkage disequilibrium (LD) patterns. We found that the accelerated evolution of brain size in hominids, is related to synchronic acceleration in the substitution rates of $A S P M$ and $M C P H 1$, and to signals of positive selection, especially in hominins. The $\mathrm{d}_{\mathrm{N}} / \mathrm{d}_{\mathrm{S}}$ and $\mathrm{LD}$ analyses in Homo detected sites under positive selection and some regions with haplotype blocks at several candidate sites surrounded by blocks in LD-equilibrium. Accelerations and signals of positive selection in $A S P M$ and $M C P H 1$ occurred in different lineages and periods being $A S P M$ more closely related with the brain evolution of hominins. MCPHI evolved under positive selection in different lineages of the Catarrhini, suggesting independent evolutionary roles of this gene among primates.
\end{abstract}

ARTICLE HISTORY

Received: $14-10-2020$

Revised: 3-03-2021

Accepted: 5-06-2021

KEYWORDS

Brain size

Homo

Microcephalyassociated genes Molecular evolution Natural selection

\section{Introduction}

The study of variation in brain size among Primates has lead to the understanding of evolutionary changes associated with the origins of human-specific traits such as cognition and language (Jones et al. 1992; Wong 2006). The human brain has tripled in size throughout the evolution of the Homininae, taking nearly seven million years (MY) to reach modern human capacity. Hominin brain started to accelerate in size since the australopithecines approximately four MY ago (Holloway et al. 2004), who had brain volume modestly larger than chimpanzees with $393 \mathrm{~cm}^{3}$ in average (McHenry 1994). Australopithecus africanus, possible immediate predecessor of Homo, had an average brain volume of $461 \mathrm{~cm}^{3}$ with some specimens reaching up to $515 \mathrm{~cm}^{3}$ (Holloway et al. 2004; Neubauer \& Hublin 2012). At the origins of Homo roughly two MY ago, a substantial enlargement of cranial capacity occurred; Homo habilis exhibited sizes of approximately $610 \mathrm{~cm}^{3}$. The transition to Homo ergaster and Homo erectus with brain size ca. $1000 \mathrm{~cm}^{3}$, seems gradual before an 
accelerated leap to Homo erectus and to the ancestor of Homo neanderthalensis and Homo sapiens at about 600000 years ago after which both species reached an average brain volume of $1400 \mathrm{~cm}^{3}$ (Falk 1983; Rightmire 1998, 2004; Neubauer \& Hublin 2012). The enlarged brain size of humans evolved in different functional areas related with communication, perception, memorization, visualization, recognition, problem solution, reasoning, and planning among others relevant in solitude survival and socialization accordingly with the cultural brain hypothesis (Schoenemann 2006; Muthukrishna et al. 2018; Neubauer et al. 2018).

Humans among mammals exhibit the highest proportion of brain size with reference to body size (Jerison 1973; Roth \& Dicke 2012) without increase in metabolic rate (Ross 1992) as it occurs in other highly cephalized mammals such as cetaceans (Gaskin 1982; Marino 2002; Figure 1). Cephalization in Primates, humans included, seems to be related with enlarged life cycles (Allman et al. 1993) that reflect low energy expenditure relative to other mammals; such low energy expenditure in turn seems associated with the early evolution of Primates in the context of lowly caloric diets, nocturnal habits, warm and humid habitats, as well as with minimization of starvation risk in unpredictable environments (Ross 1992; Ward et al. 2004; Pontzer et al. 2014).
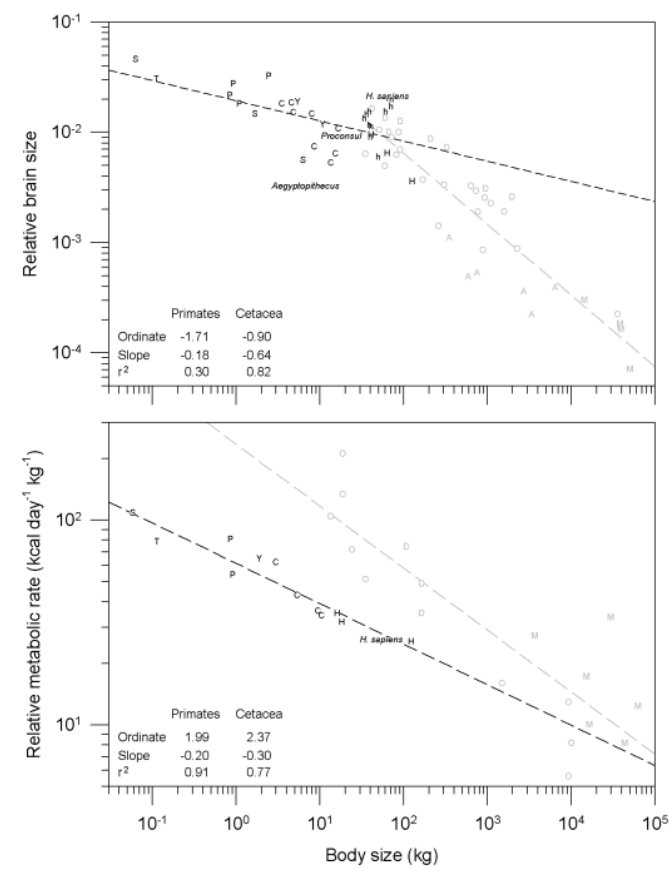

Figure 1. Allometry of the relative brain size (brain size / body size) and the relative-resting metabolic rate (metabolic rate / body size) in Primates (black) and Cetacea (gray). Data and original sources are provided in Supplementary
Table S2 and the references section. Primates symbols are $\mathrm{S}$ for Strepsirrhini, $\mathrm{T}$ for Tarsiidae, $\mathrm{P}$ for Platyrrhini, Y for Hylobatidae, $\mathrm{C}$ for Cercopithecidae, $\mathrm{H}$ for Hominidae, and $\mathrm{h}$ for Homininae. Cetacea symbols are A for Archaeoceti, M for Mysticeti, O for Odontoceti except Delphinidae, and D for Delphinidae. Dashed lines indicate linear regressions in the log-log plot with parameters shown in the graphs' lower-left corners. Primates data were compiled by Leyva Hernández (2016) and Cetacea data by Medrano González (2009).

At least 12 loci in humans are involved in the morphology and size of the cranium as indicated by the recessive mendelian inheritance of microcephaly (Jackson et al. 2002; Thornton \& Woods 2009). Among these, the abnormal spindle-like microcephalyassociated gene (ASPM) encodes a protein that is involved in cell division being especially important for division of developing brain cells. A knockout ferret, whose Aspm protein sequence is homologous to the human one, exhibits severe microcephaly with brain cortical surface and thickness diminished by 25-40\% like human patients also show (Desir et al. 2008; Passemard et al. 2016). The role of $A S P M$ in brain development begins during neurogenesis modulating the activity of the mitotic spindle during neuron division, thereby affecting brain size and neuronal density; when mutations occur in this gene, the size of the brain is altered (Ponting \& Jackson 2005).

Microcephalin $1(\mathrm{MCPHI})$ is another gene that is expressed during neurogenesis that regulates the progression of cell cycle (Arroyo et al. 2017). When $M C P H I$ function is deficient, the chromosome condensation is uncoupled from the cell cycle progression resulting in cells that precipitately condense their chromosomes throughout the G2-phase provoking decondensation delay at the end of mitosis; during brain development; mutations in this gene can induce cell division instability causing primary microcephaly (Lin et al. 2005; $\mathrm{Xu}$ et al. 2004). As in other genes associated with development of the nervous system, strong positive selection, and an accelerated substitution rate of $M C P H 1$ among hominins (Evans et al., 2005; Evans et al., 2006), has led to regard this gene as important in the evolution of human brain.

In humans, microcephaly seems epistatic (Bond \& Woods, 2006), even though neuroepithelial cells are not affected owing to their elongated morphology (Fish et al. 2006). Such effects are reduced by the evolution of protein-encoding genes (Hoekstra \& Coyne, 
2007), mutations that affect the regulation of gene expression (Haygood et al. 2007; Somel et al., 2009), and other genetic mechanisms apparently related to macroevolutionary changes (Montgomery \& Mundy, 2010).

Given the importance of ASPM and MCPHI for studying the genetical basis of human brain evolution, here we reconstructed phylogenies of these two genes in the Catarrhini to examine the relationship between nucleotide substitution rates at different codon positions and evolutionary change in brain size. We included eight Neanderthals, one Denisovan, one archaic $H$. sapiens, and 10 modern $H$. sapiens contributing to previous analyses (e.g. Montgomery et al. 2011). We also identified signals of evolutionary forces for both genes especially searching for targets of positive selection through the $d_{N} / d_{S}$ ratio across the Catarrhini. These two analyses were made on exon 3 of the $A S P M$ gene, as well as on exons 8 and 11 of the $M C P H 1$ gene since they are the most polymorphic and appropriate for the intended inferences. We also added examination of selection signals through linkage disequilibrium (LD) in archaic and modern Homo species across the complete sequences of both genes.

Materials and methods

\section{Data}

We retrieved 31 sequences of the $A S P M$ or $M C P H 1$ genes in 15 primate species from the National Center for Biotechnology Information (NCBI, https://www.ncbi.nlm.nih.gov), the European Bioinformatics Institute (EBI, ftp://ftp.ebi.ac.uk), the Max Planck Society for Evolutionary Anthropology (http://cdna.eva.mpg.de), and the 1000 genome project (http://www.internationalgenome.org) through the links and access codes described in Supplementary Table S1. Non-human species sampled included Hominidae: Pan troglodytes, Gorilla gorilla, Pongo pygmaeus; Hylobatidae: Hylobates lar, Hylobates hoolock; Cercopithecidae: Chlorocebus aethiops, Erythrocebus patas, Macaca mulatta, Papio anubis, Semnopithecus entellus, Colobus guereza; Aotidae: Aotus sp. The human sequences pertain to 10 modern $H$. sapiens from the 1000 genome project panel (Yoruba and Esan from Nigeria, Mandinka from Gambia, Han from China, and Finland), Sunghir-1, eight $H$. neanderthalensis (the Neanderthal reference genome, Altai, Goyet, Les Cottés, Mezmaiskaya -1 and -2, Spy-1, Vindija 33.19), and the Denisova-3 individual from Siberia.
We also compiled in scientific literature data on body and brain sizes from 34 primate species as well as the resting metabolic rate from 13 primate species (Figure 1; Supplementary Table S2). Data include the taxa Strepsirrhini and Haplorrhini: Tarsiiformes and Simiiformes: Platyrrhini and Catarrhini: Aegyptopithecus, Cercopithecidae, Hylobatidae, Proconsul, and Hominidae. These data were contrasted with body and brain sizes from 37 species of cetaceans and the resting metabolic rate of seven cetacean species (Figure 1; Supplementary Table S2). The age estimations of species origins and phylogenetic branches were obtained from the TimeTree gateway (http://www.timetree.org; Kumar et al. 2017), the Smithsonian Institution webpage (https://humanorigins.si.edu), and The Cambridge Encyclopedia of Human Evolution (Jones et al. 1992).

\section{Phylogenetic analysis}

We employed exon 3 of the ASPM gene, and exons 8 and 11 of the $M C P H 1$ gene for phylogenetic analyses looking to estimate molecular rates since these fragments were available for more primate species and also because their larger degree of polymorphism makes them more adequate for phylogenies reconstruction and examination of nucleotide changes. A total of 1236 bp in 13 species corresponded to the ASPM exon 3, $1089 \mathrm{bp}$ in nine species corresponded to the $M C P H 1$ exon 8 , and 159 bp in 12 species corresponded to the $M C P H 1$ exon 11 . We built one phylogeny of the $A S P M$ exon 3 to maximize taxon sampling (13 species), and one phylogeny of the three exons (2484 bp) in seven species and one genus to maximize the information on DNA sequence change, especially to compare the changes among lineages in both genes. The $A S P M$ sequence of $H$. lar and the MCPHI sequence of $H$. hoolock were merged to be examined as Hylobates spp. Since we were interested in the estimation of the nucleotide substitution rates, i.e., molecular clocks, in phylogenetic branches, we employed only one sequence per species. Nucleotide sequences were aligned using the CLUSTALW software (Larkin et al. 2007) allowing only 3 bp gaps as they are equivalent to one amino-acid residue.

We constructed the two phylogenetic trees using program MRBAYES 3.2.7 (Huelsenbeck \& Ronquist 2001) in two independent runs with four Markov chains, a temperature parameter of 0.5 during 20 million generations, and a sampling frequency of $1 / 1000$ discarding the initial $25 \%$ of trees. Sequences were partitioned by the three codon positions of both genes employing for each the general 
reversible model (GTR) with inverse gamma distribution as well as a relaxed clock variation with independent gamma rates. The two sequence datasets ran in MRBAYES yielded phylogenies that closely resemble the known species phylogeny (e.g., Perelman et al. 2011) but we had to enforce the Tribes Cercopithecini and Papionini to consistently estimate nucleotide change and relate it with brain size evolution. This procedure was based on Delson (1992), Page et al. (1999), and Xing et al. (2005). Each phylogenetic tree was visualized using FIGTREE 1.4.3 rooting the $A S P M$ tree with Aotus sp and the ASPM $M C P H 1$ tree with the branch between Hominoidea and Cercopithecoidea. The consistency and retention statistics as well as the mapping of nucleotide changes for the phylogenies obtained were determined using MACCLADE 4.06 (Maddison \& Maddison 2003).

\section{Comparison of anatomical and molecular rates}

Two nucleotide substitution rates for each gene in each branch of both trees were determined dividing branch length by the time elapsed between the branch's flanking nodes or ends: 1) One rate of the added lengths of codon positions 1 and $2\left(r_{1,2}\right)$; this is approximately the clock of non-synonymous substitutions, and 2) Another rate of the codon position 3 length which is approximately the clock of synonymous substitutions $\left(\mathrm{r}_{3}\right)$. Although related, notice that such rates are not $d_{N}$ and $d_{S}$ of the selection analysis. We used the difference $r_{1,2}-r_{3}$ to describe the rate and mode of molecular evolution. Similar to the analysis of the $d_{N} / d_{S}$ ratio, negative values of $r_{1,2}-r_{3}$ indicate purifying selection, zero indicates neutrality and positive values indicate positive selection.

We determined a measure of encephalization for the specific set of 34 primate species compiled in Figure 1 and Supplementary Table $\mathrm{S} 2$ as the residual value of relative brain size with reference to the relative brain size given by the regression in Figure 1. Thereafter, we estimated encephalization in each node of both phylogenetic trees following one of three alternative procedures: 1) Use of the closest fossil data that were Homo heidelbergensis in the node between $H$. sapiens and $H$. neanderthalensis, Sahelanthropus tchadensis in the node between Homininae and $P$. troglodytes, Proconsul africanus in the origins of Hominidae and Aegyptopithecus zeuxis in the origins of Hominoidea, 2) Interpolation between nodes weighted by time difference as was done among the Hominidae, and 3)
Average between the two branches in a node; this had to be done in the Cercopithecidae for which the scarce fossil data and incomplete species sampling impede the other two procedures. An encephalization rate was then calculated as the encephalization difference between the flanking nodes or ends of each branch, divided by the time elapsed in each branch. Molecular and encephalization rates were finally plotted with lines depicting the phylogeny topology and making a linear regression of the encephalization rate with reference of the molecular rate.

\section{Selection analysis}

From the phylogenies mapping done with MACCLADE 4.06, initial examination of selection among different taxa was made examining the branch length proportions of codon position 1 / codon position 3 and codon position 2 / codon position 3, this is approximately the non-synonymous / synonymous lengths. We also examined the transversions / transitions ratio as well as the rates of total changes and transversions per lineage per MY.

Further in the set of the whole gene sequences from all the human individuals described above, selection signals were evaluated for neutrality and positive selection using the CODEML program included in the PAML package (Yang 2007). The nested codon models were performed for the ratio of nonsynonymous $\left(\mathrm{d}_{\mathrm{N}}\right)$ to synonymous $\left(\mathrm{d}_{\mathrm{S}}\right)$ substitution rates, $\omega=\mathrm{d}_{\mathrm{N}} / \mathrm{d}_{\mathrm{s}}$, which were compared using the average likelihood ratio test (Anisimova et al. 2001). Neutrality was tested with the M1a model, and was compared with the M2a model for sites that were putatively under positive selection. Selective pressure was evaluated using the ratio $\omega$. When the value of $\omega$ is significantly lower than 1 , the region has undergone purifying selection; when $\omega$ equals 1 , the region is in neutral selection; and when $\omega$ is significantly greater than 1 , the region is under positive selection (Yang \& Bielawski 2000). The confidence interval of the p-value was tested by means of PAML using CONSEL v0.1 (Shimodaira \& Hasegawa 2001).

Because exonic regions are treated, the intragenic recombination was tested by RDP (Martin \& Rybicki 2000), GENECONV (Padidam et al. 1999), CHIMAERA (Pettersen et al. 2004), and BOOTSCAN (Salminen et al. 1995), which comprise a group of programs implemented in the RDP3 package (Martin et al. 2010; Martin et al. 2015). We also tested targets of positive selection according to the 
patterns of LD in the DNA sequences, because fixation of a beneficial allele causes an increased level of LD around the selected site (Slatkin 2008). LD was tested by the squared correlation coefficient ( $\mathrm{R}^{2}$; Ramos-Onsins \& Rozas 2001) between nucleotides using DNaSP (Rozas \& Rozas 1999). For plotting, the $R^{2}$ values of all pairwise combinations of nucleotides were binned and averaged in cells of $1 \mathrm{~kb} \times 1 \mathrm{~kb}$ according to the physical distances separating nucleotides; such binning and averaging procedures were carried out using the PROMELD program developed by author LMG. Mean $\mathrm{R}^{2}$ values in comparisons of the $1 \mathrm{~kb} \times 1 \mathrm{~kb}$ cells were then plotted as one half-matrix according to the method described by Miyashita \& Langley (1988) using the SIGMAPLOT 10.0 program.

\section{Results}

\section{Gene phylogenies}

The phylogenetic tree based on 1236 nucleotides of ASPM exon 3 in 13 species of primates appeared the same as the known phylogeny of this group (e.g. Perelman et al. 2011), and exhibited high posterior probabilities (Figure 2). The log-likelihood average $(\mathrm{LnL})$ among the retained last $75 \%$ of trees was -2767.75 (Supplementary Figure S1; $\mathrm{p}<0.001)$, the consistency and retention indices were both 0.94 and thus, the rescaled consistency index was 0.88 . Using Aotus for rooting, the tree distinguished Haplorrhini and Catarrhini as well as Cercopithecoidea and Hominoidea within Catarrhini. Colobinae and Cercopithecinae were distinguished among Cercopithecidae, whereas Hylobatidae and Hominidae were distinguished within Hominoidea. Homininae was also identified in the ASPM exon 3 tree with $P$. troglodytes as its sister species, and $P$. pygmaeus as the most external hominid. Recall that the Tribes Cercopithecini and Papionini were enforced (Figure 2).

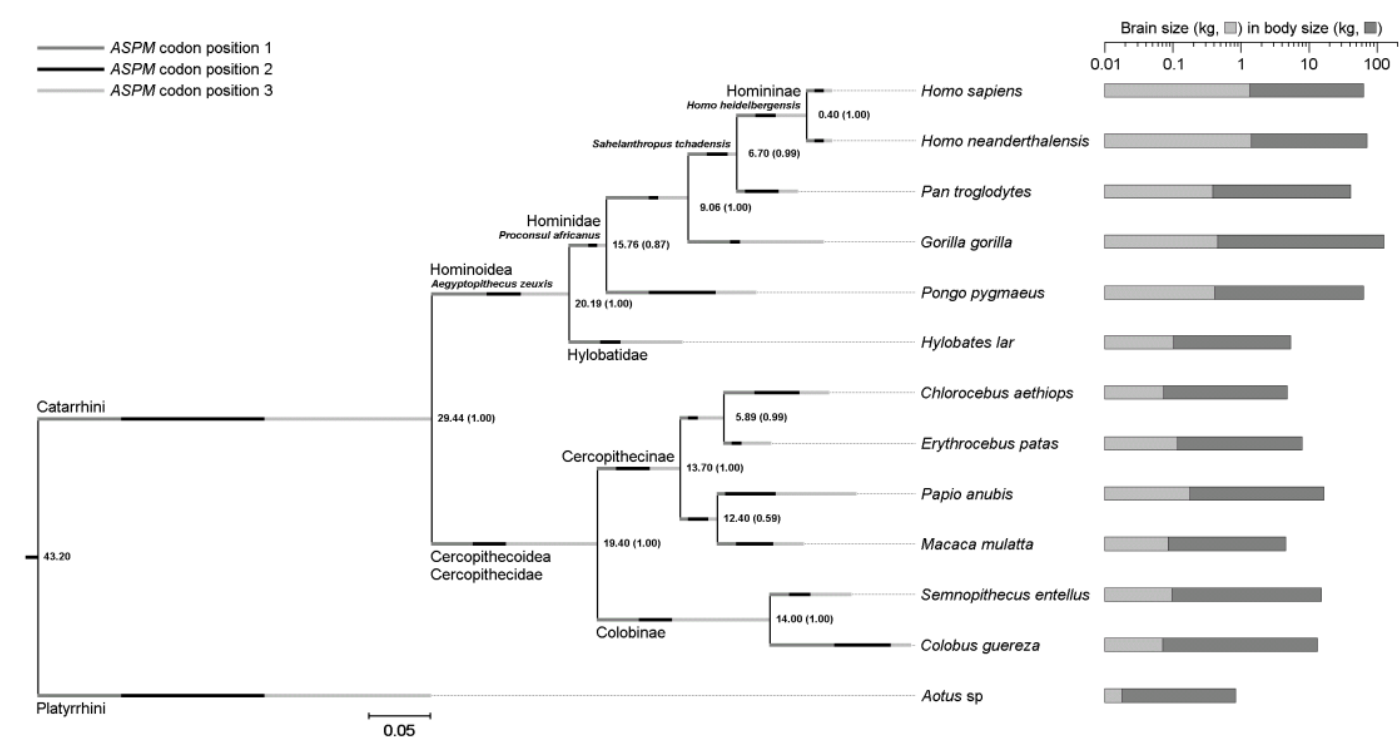

Figure 2. Bayesian phylogenetic tree of the abnormal spindle-like microcephaly-associated (ASPM) gene exon 3 for 13 primate species. Branch lengths are proportional to molecular change scaled with the bottom bar and indicated for the change in codon positions 1 (mid gray), 2 (black) and 3 (light gray). Brain and body sizes were taken from Supplementary Table S2 and are shown adjacent to branch tips in logarithmic scale to better appreciate their variation. Node data indicate time in million years (MY), taken from the TimeTree gateway, and the posterior probability is shown within parentheses.

We plotted the ASPM tree with branch lengths proportional to molecular change and observed an accelerated molecular rate through the Homininae lineage among Hominoidea. Such acceleration is apparently correlated with increased brain size for all the Hominidae including $G$. gorilla for which the low encephalization value is due to increased body size. We also observed a degree of molecular acceleration in the Colobinae, but it appeared unrelated to a change in brain size (Figure 2).
The phylogenetic tree based on 2482 nucleotides of the ASPM exon 3 and $M C P H 1$ exons 8 and 11 , is the same as the known phylogeny of the eight species comprised in this analysis, and it also exhibited high posterior probabilities (Figure 3). The LnL average among the last $75 \%$ of trees was 4912.08 (Supplementary Figure S1; p < 0.001), the consistency and retention indices were 0.95 each for the rescaled consistency index to be 0.91. This tree was rooted with the branch 
separating Cercopithecoidea and Hominoidea and it also distinguished Colobinae and Cercopithecinae within Cercopithecidae, whereas Hylobatidae and Hominidae were distinguished within Hominoidea. Homininae was also identified in this tree joined with $G$. gorilla as the only other hominid sampled. The Tribes Cercopithecini and Papionini had also been enforced in this tree (Figure 3 ).

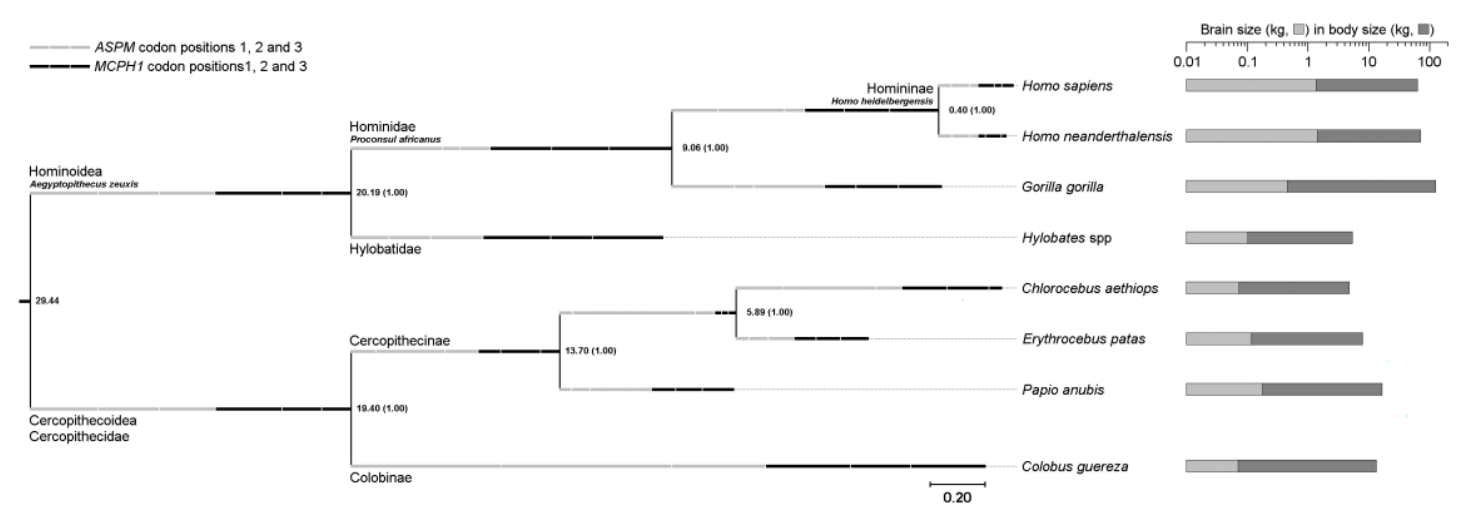

Figure 3. Bayesian phylogenetic tree of the joint ASPM exon $3-M C P H 1$ exons 8 and 11 for eight primate species. Branch lengths are proportional to molecular change scaled with the bottom bar and indicated for the change in codon positions 1, 2 and 3 indicated with branch breaks for ASPM (light gray) and $M C P H 1$ (black). Brain and body sizes were taken from Supplementary Table S2 and are shown adjacent to branch tips in logarithmic scale to better appreciate their variation. Node data indicate time in million years (MY), taken from the TimeTree gateway, and the posterior probability within parentheses.

The joint ASPM - MCPHI tree also showed an accelerated molecular rate in the Homininae among the Hominoidea in relation with increased brain size in the Hominidae. A molecular acceleration was also observed in $C$. guereza and $C$. aethiops with no relation to increment in brain size (Figure 3).

\section{Anatomical and molecular rates}

The tree of the ASPM gene alone contains 23 branches with lengths modelled in each of the three codon positions. All branches of the ASPM phylogenetic tree in Figure 2, showed positive values of the rates-differential $r_{1,2}-r_{3}$ and the encephalization rate. However, there is not a sustained increment of the molecular differential $r_{1,2}-r_{3}$ or the encephalization rate along time for the different lineages (Figure 4). The differential $\mathrm{r}_{1,2}-\mathrm{r}_{3}$ for the ASPM gene was also highly correlated with the encephalization rate in the evolution of the Hominoidea. Such correlation and the slope were almost nihil for the Cercopithecoidea. The differential $r_{1,2}-r_{3}$ and the encephalization rate also exhibited acceleration among the Homininae and this apparently yields the largest contribution to the high correlation of molecular and anatomical rates in the Hominoidea.

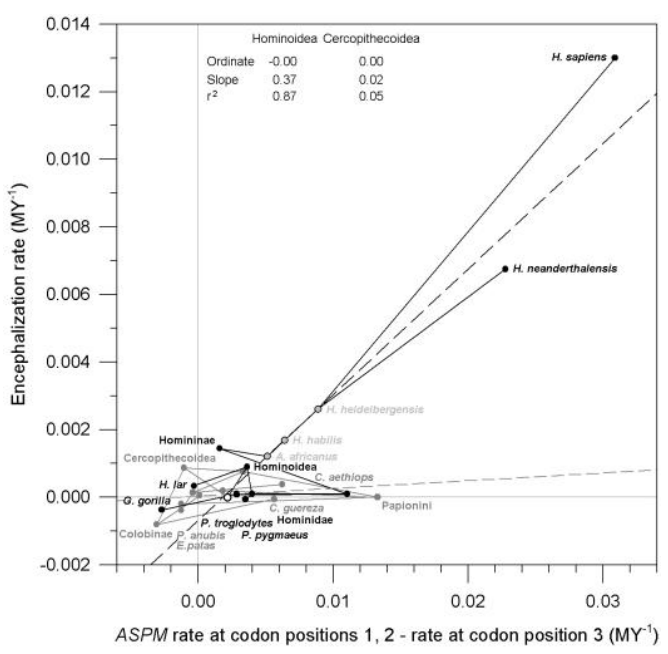

Figure 4. Plot of the rates difference $r_{1,2}-r_{3}$ and the encephalization rate for the $A S P M$ gene phylogeny of 13 species. The phylogeny branches correspond to black (Hominoidea) and gray (Cercopithecoidea) dots connected by the tree topology. Linear regressions are indicated with dashed lines in gray for the Cercopithecoidea and black for the Hominoidea with parameters shown in the graph upper-left corner. The root branch is indicated with a white circle and the encephalization data of three ancient hominins were interpolated with gray circles.

The joint ASPM - MCPHI tree contains 13 branches with lengths modelled in each of the three codon positions of both genes. All 
branches of the $A S P M-M C P H 1$ phylogenetic tree in Figure 3, also showed positive values of the molecular differential $r_{1,2}-r_{3}$ and the encephalization rate for both genes although with fluctuating changes along the different lineages (Figure 5). The differential $r_{1,2}-r_{3}$ for both genes was too highly correlated with the encephalization rate in the evolution of the Hominoidea, especially for the ASPM gene.
The slope and regression index for the Cercopithecoidea were also lower as compared with Hominoidea but considerably higher than the correlation in the Cercopithecoidea at the sole $A S P M$ tree, especially for the $M C P H 1$ gene (Figure 5). The differential $r_{1,2}-r_{3}$ and the encephalization rate in both genes also showed acceleration among the Homininae (Figure 5).

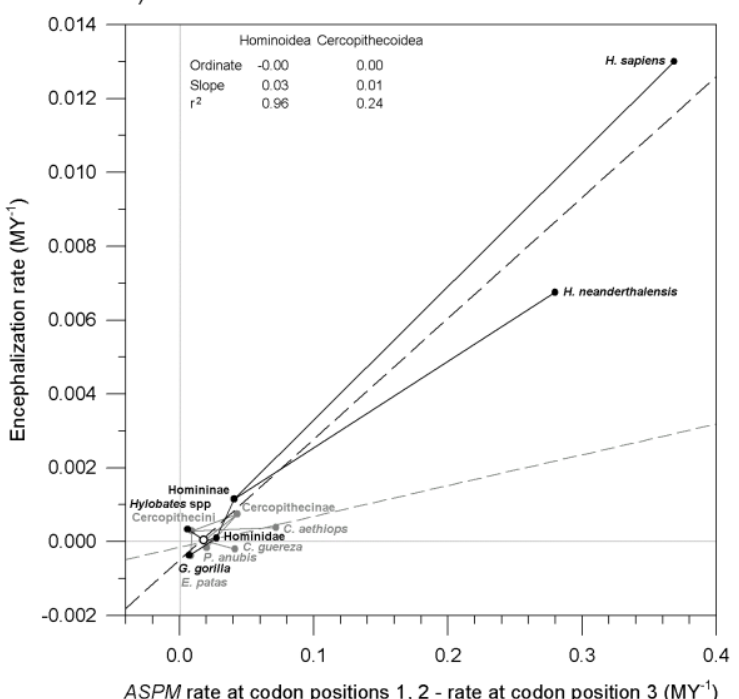

b)

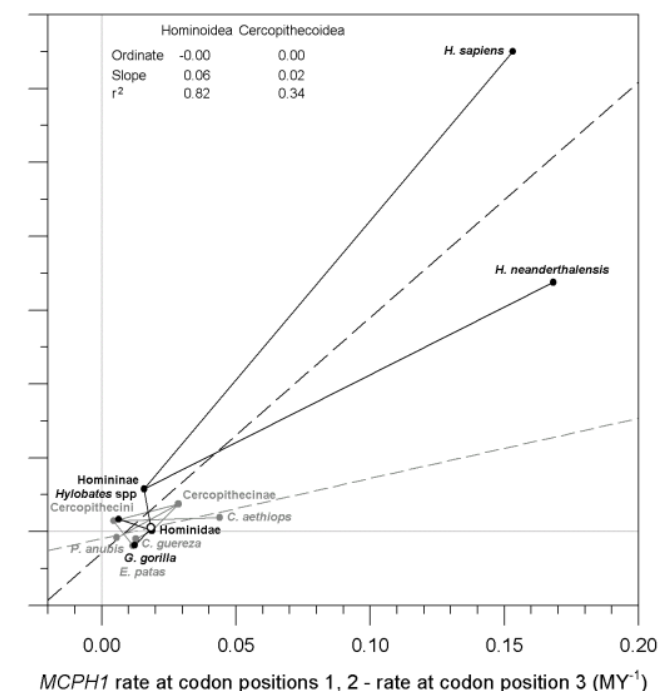

Figure 5. Plots of the rate differences $\mathrm{r}_{1,2}-\mathrm{r}_{3}$ and the encephalization rates for the joint ASPM (a)MCPH1 (b) gene phylogeny of eight species. The phylogeny branches correspond to black (Hominoidea), and gray (Cercopithecoidea) dots connected by the tree topology. Linear regressions are indicated with dashed lines in gray for the Cercopithecoidea and black for the Hominoidea with parameters shown in the graphs' upper-left corners. The root branch is indicated with a white circle.

\section{Selection mode}

All branch lengths of the ASPM tree summed are 2.29 of which 0.92 is for the Cercopithecoidea and 0.74 for the Hominoidea (Table 1). The length ratios for codon position $1 /$ codon position 3 and codon position 2 / codon position 3 are larger in the Hominoidea compared to Cercopithecoidea and larger in the Homininae compared to all Hominoidea (Table 1). Total traced unambiguous changes for the
ASPM tree were 183 and the transversions / transitions ratio is also lager in the Homininae compared with all Hominoidea, and larger in Hominoidea compared with Cercopithecoidea. Larger values for the Homininae and lower for the Cercopithecoidea occur also for the rate of transversions per lineage-MY (Table 1). However, the rate of changes per lineage-MY is slower for the Homininae and larger for the Cercopithecoidea (Table 1).

\begin{tabular}{lcccc}
\hline & Whole tree & Cercopithecoidea & Hominoidea & Homininae \\
\hline Total branch length & 2.288 & 0.916 & 0.744 & 0.111 \\
BL cp1 / BL cp3 & 0.646 & 0.560 & 0.753 & 0.827 \\
BL cp2 / BL cp3 & 0.759 & 0.760 & 0.759 & 0.862 \\
Total changes & 183 & 66 & 54 & 4 \\
Transitions (Tr) & 126 & 48 & 35 & 2 \\
Transversions (Tv) & 57 & 18 & 19 & 2 \\
Tv / Tr & 0.452 & 0.375 & 0.543 & 1.000 \\
Changes / Lineage-MY & 0.784 & 0.696 & 0.662 & 0.563 \\
Tv / Lineage-MY & 0.244 & 0.190 & 0.233 & 0.282 \\
Lineage time (MY) & 233.34 & 94.83 & 81.55 & 7.10 \\
\hline
\end{tabular}

Table 1. Modelled branch lengths (BL) per codon position (cp), traced unambiguous changes and lineage-times in million years (MY) for the Bayesian phylogeny of the ASPM-gene exon 3 (Figure 2). 
All branch lengths of the joint ASPM $M C P H 1$ tree summed up 7.49 for $A S P M$ of which 4.39 is for the Cercopithecoidea and 3.10 for the Hominoidea, whereas for $\mathrm{MCPHI}$ lengths summed up 5.49, 2.58 for Cercopithecoidea and 2.90 for Hominoidea (Table 2). As for the ASPM gene, the length ratios for codon position $1 /$ codon position 3 are also larger in the Hominoidea compared to Cercopithecoidea and larger in the Homininae compared to Hominoidea; the codon position 2 / codon position 3 proportion is larger for the Homininae and smaller in the Hominoidea. With regard to the $M C P H 1$ gene, the length proportions of codon positions 1 and 2 with respect to codon position 3 , are all larger in the Cercopithecoidea and similar among the Hominoidea and Homininae (Table 2). The joint tree exhibited 215 unambiguous changes in total, 97 for the ASPM gene and 118 for the MCPH1 gene. The ratio of transversions / transitions for the ASPM gene is also lager in the Homininae compared with all Hominoidea, and larger in Hominoidea compared with Cercopithecoidea. In the $M C P H I$ gene, the transversions / transitions proportion is larger for the Homininae compared with Hominoidea but Cercopithecoidea in this case exhibited the largest proportion (Table 2). For the ASPM gene, the rate of transversions per lineage-MY is also larger for the Homininae and lower for Cercopithecoidea, whereas the rate of changes per lineage-MY is slower for the Homininae and larger for the Cercopithecoidea (Table 2). In the MCPHI gene, the rates of changes and transversions per lineage-MY are both larger for the Homininae and slower for the Cercopithecoidea (Table 2).

\begin{tabular}{lcccc}
\hline \multicolumn{1}{c}{$\boldsymbol{A S P M}$} & Whole tree & Cercopithecoidea* & Hominoidea* & Homininae \\
\hline Total branch length & & & & \\
BL cp1 / BL cp3 & 7.495 & 4.392 & 3.102 & 0.849 \\
BL cp2 / BL cp3 & 1.223 & 1.084 & 1.400 & 2.110 \\
Total changes & 1.500 & 1.804 & 1.112 & 3.084 \\
Transitions (Tr) & 97 & 48 & 29 & 5 \\
Transversions (Tv) & 71 & 39 & 19 & 3 \\
Tv / Tr & 26 & 9 & 10 & 2 \\
Changes / Lineage-MY & 0.366 & 0.231 & 0.526 & 0.667 \\
Tv / Lineage-MY & 0.753 & 0.822 & 0.562 & 0.529 \\
$\quad$ MCPH1 & 0.204 & 0.154 & 0.201 & 0.211 \\
Total branch length & & & & \\
BL cp1 / BL cp3 & 5.486 & 2.584 & 2.902 & 0.724 \\
BL cp2 / BL cp3 & 1.206 & 1.363 & 1.087 & 1.000 \\
Total changes & 1.021 & 1.164 & 0.913 & 1.050 \\
Transitions (Tr) & 118 & 45 & 48 & 11 \\
Transversions (Tv) & 75 & 28 & 33 & 7 \\
Tv / Tr & 43 & 17 & 15 & 4 \\
Changes / MY lineage & 0.573 & 0.607 & 0.455 & 0.571 \\
Tv / MY lineage & 0.925 & 0.771 & 0.963 & 1.163 \\
Lineage time (MY) & 0.337 & 0.291 & 0.301 & 0.423 \\
\hline
\end{tabular}

Table 2. Modelled branch lengths (BL) per codon position (cp), traced unambiguous changes and lineage-times in million years (MY) for the joint Bayesian phylogeny of the ASPM exon $3-M C P H 1$ exons 8 and 11 (Figure 3). * Not including root branch.

Our ASPM gene phylogeny allowed the identification of a site under positive selection (Table 3). However, when assessing the phylogeny without Aotus, we identified six non-synonymous changes in six different amino acids that resulted in $\omega=\mathrm{d}_{\mathrm{N}} / \mathrm{d}_{\mathrm{S}}>1(\mathrm{p}>$ $0.95)$. This difference in selected sites with or without the haplorrhine external group (Table 3) suggests an important selection effect in the Catarrhini. The shorter ASPM tree with no haplorrhine external group exhibited fewer molecular changes among the hominins and cercopithecids, suggesting positive selection, whereas Hylobates, Gorilla, and Pongo exhibited more molecular changes and $\omega<1$, indicating purifying selection. These results therefore indicate heterogeneous evolution among primate lineages as also indicated by the molecular and anatomical rates fluctuating along the phylogeny (Figures 4, 5).

When we applied the M2 model test in the PAML program to $M C P H 1$ exon 8 , it revealed that two amino acids had been positively selected ( $\mathrm{p}>0.95)$. MCPHI exon 11 exhibited three positively selected amino acids ( $\mathrm{p}>$ $0.95)$, as well as several sites under purifying selection $(\omega<1$; Table 3$)$. 


\begin{tabular}{lcccc}
\hline & $\boldsymbol{A S P M}$ exon 3* & $\begin{array}{c}\boldsymbol{A S P M} \text { exon } \\
\mathbf{3}^{* *}\end{array}$ & $\begin{array}{c}\text { MCPH1 } \\
\text { exon 8 }\end{array}$ & $\begin{array}{c}\boldsymbol{M C P H 1} \\
\text { exon 11 }\end{array}$ \\
\hline LnL M1a (neutrality) & -5847.22 & -2576.30 & -1878.01 & -270.75 \\
LnL M2a (positive selection) & -5852.60 & -2576.30 & -1876.96 & -270.62 \\
$p$ & $<0.001$ & 0.124 & 0.027 & 0.160 \\
Proportion of sites with $w>1$ & 0.617 & 0.513 & 0.741 & 1.000 \\
$w$ & 2.366 & 1.523 & 3.604 & 1.804 \\
Positively selected sites & 31L, 83G, & $355 \mathrm{~S}$ & $150 \mathrm{G}, 199 \mathrm{R}$ & $3 \mathrm{~V}, 4 \mathrm{~V}$, \\
& 123L, 188I, & & & $18 \mathrm{D}$ \\
\hline
\end{tabular}

Table 3. Test of neutrality and selection models for abnormal spindle-like microcephaly-associated $(A S P M)$ and microcephalin-1 $(M C P H 1)$ genes in Primates. *Including Aotus as external group. **Excluding Aotus as external group.

\section{Recombination and LD}

It was possible that the exons studied may have exhibited signals of crosslinking during the recombination process. Therefore, we evaluated the three exons of the two genes by sequence simulation and by permutation tests of the alignment and phylogeny using the RDP3 program (Martin et al. 2010). The coding regions of the ASPM and MCPHI genes, which had signals of selection did not show evidence of recombination or gene conversion according to the analysis performed using the RDP3 program.

The neutral model, commonly used as the null hypothesis considers no recombination, and panmictic populations of finite size; therefore, the effect of intragenic recombination is poorly explored by this model. Moreover, tests based on haplotypes or LD are strongly affected by recombination, which decreases $\mathrm{LD}$ by breaking down the haplotypes formed. A $\mathrm{ZnS}$ statistic approaching 1 in a maximal $L D$ value also has relatively high power to detect soft sweeps when a locus experiences recurrent beneficial mutations (Pennings \& Hermisson 2006). Low $\mathrm{ZnS}$ values suggest that all polymorphic loci are variable in maximal $\mathrm{LD}$ (Figures 6, 7).

In the $62.5-\mathrm{kb}$ region of the complete $A S P M$ sequence 366 polymorphic sites were found among hominins with a $\mathrm{ZnS}$ value of 0.19 (Kelly 1997), and a Za value of 0.21 (Rozas et al. 2001). The regression equation for $R^{2}$ values was $\mathrm{Y}=0.1960-0.0003 \mathrm{X}$ with 66795 points from pairwise comparisons, of which $\mathrm{R}^{2}$ values of 1.0 were significant in 16767 cases according to the $\chi^{2}$ test $(0.01<\mathrm{p}<0.05)$; this was nearly $27 \%$ of the entire region. A higher than expected LD led to the identification of other strong selection signals not observed with $\omega$ inside a $1.2-\mathrm{kb}$ region across ancestral sites in the ASPM gene (Figure 6; Table 3).

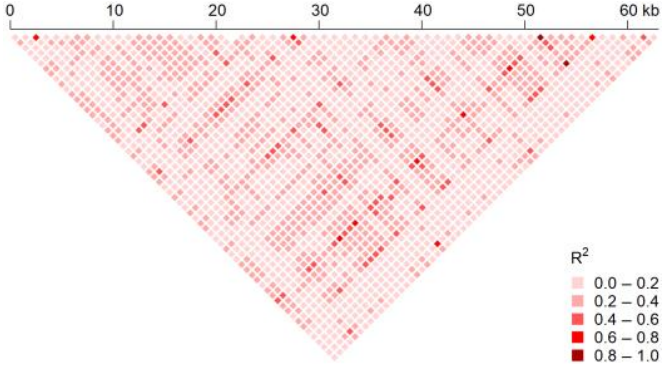

Figure 6. Linkage disequilibrium (LD) plot of the ASPM gene among archaic and modern humans. Cells represent average $\mathrm{R}^{2}$ values in $1.0 \mathrm{~kb}$ bins.

Our LD metrics in the 242-kb region comprising the whole $M C P H 1$ gene revealed signals of candidate regions for selection among Homo, some of which had statistically significant values according to the LD analysis. The obtained values-i.e., $\mathrm{ZnS}=$ 0.098, $\mathrm{Za}=0.182$, Wall's $\mathrm{B}=0.112$, and Wall's Q $=0.129$-resulted from 2727 polymorphisms, with some sites showing significant LD, mainly at the $3^{\prime}$ end of the MCPH1 gene. The regression equation for $\mathrm{R}^{2}$ values was $\mathrm{Y}=0.1005-0.000 \mathrm{X}$ with 3716901 points (Figure 7; Table 3).

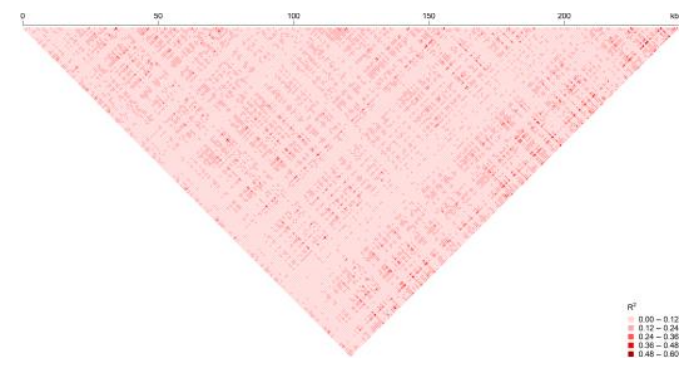

Figure 7. Linkage disequilibrium (LD) plot of the microcephalin-1 (MCPHI) gene among archaic and modern humans. Cells represent average $\mathrm{R}^{2}$ values in $1.0 \mathrm{~kb}$ bins.

In summary, LD analysis identified a few selective-sweep candidates surrounded by a local variable recombination rate that equilibrated the frequencies of the haplotypes; 
this suggests an early history of selection in Homo at the genetic regions here studied.

\section{Discussion}

Our phylogenies of the ASPM exon 3 and MCPH1 exons 8 and 11 in the studied Primates showed the topology of the known organismal phylogeny (e.g., Perelman et al. 2011), although with a minor inconsistency among three cercopithecids that was corrected through a topology forcing needed to compare molecular and anatomical rates. Our phylogenies also revealed an acceleration in the nucleotide substitution rate in $A S P M$ and $M C P H 1$ that correlated with the general trend of increasing cranial volume among hominids, especially in the hominins, and showed molecular accelerations among certain cercopithecids and hominids not related with encephalization but to body size (e.g., gorilla) or polygyny (e.g., gorilla and cercopithecids; Figures 2, 3). In mammals, large body size is associated with small populations, which together with social fragmentation of populations and polygyny may reduce the effective population size and hence increase the rates of chromosomal and nucleotide evolution (Wilson et al. 1975; Bush et al. 1977; Charlesworth 2009; Woolfit 2009). The gorilla in particular exhibits autoapomorphic increase in body size as well as increase in the absolute size of its brain that seems associated with acceleration of $A S P M$ but not of $M C P H 1$ (Figures 2, 3) as noticed also by Kouprina et al. (2004).

The differential $r_{1,2}-r_{3}$ for the ASPM and $M C P H 1$ genes was correlated with the encephalization rate only among the Hominoidea (Figures 4, 5) with both rates being accelerated among the Homininae. The interpolation of three ancient hominins in the plot for the phylogeny of the sole ASPM exon 3 with 13 species suggests that molecular and brain size evolution accelerated gradually but rapidly since the origins of hominins approximately seven MY ago (Figure 4). Most of the correlation between the acceleration of substitution rates in $A S P M$ and $M C P H 1$ genes and increased cranial volume seems due to their acceleration in the Homininae (Figures 4, 5) for which the role of these genes in neurogenesis is known (Dorus et al. 2004; Evans et al. 2005; Evans et al. 2006; Desir et al. 2008; Arroyo et al. 2017).

Across species, the proportions of branch lengths for codon position 1 / codon position 3 and codon position $2 /$ codon position 3 were larger in the Homininae and shorter in the Cercopithecoidea at the ASPM exon 3 (Table
1). Larger values for the Homininae and lower for the Cercopithecoidea occur also for the transversions / transitions ratio and for the rate of transversions per lineage-MY. However, the rate of changes per lineage-MY is slower for the Homininae and larger for the Cercopithecoidea (Table 1) suggesting that increased branch lengths in the Homininae lineage are not related to a general acceleration of the ASPM molecular clock but to increased changes in non-synonymous sites. Similar results were obtained for the $A S P M$ exon 3 in the joint $A S P M-M C P H 1$ phylogeny (Table 2). For the $M C P H I$ exons 8 and 11 however, the ratios of branch length for codon position 1 / codon position 3 and codon position 2 / codon position 3 as well as the transversions / transitions were larger in the Cercopithecoidea. The rate of transversions per lineage-MY in the MCPHI exons 8 and 11 is higher in the Homininae together with the rate of changes per lineage-MY and this impedes the detection of a specific increase in the mode of molecular change in the Homininae (Table 2) besides acceleration. This suggests that $A S P M$ and $M C P H 1$ were involved in the evolution of encephalization in different primate lineages and periods being $A S P M$ more closely related with the brain evolution of the Homininae.

The $d_{N} / d_{S}$ ratio revealed a few sites under positive selection among purifying selection at most non-neutral sites (Table 3). The traced molecular changes in our phylogenies indicated few changes among Cercopithecidae and Hylobatidae, which have similar cranial capacities, whereas there were more molecular and phenotypic changes in the Hominidae. A combination of strong and relaxed purifying selection, as well as positive selection appear to have driven fast orthogenetic and cladogenetic change in the genetic sequences studied, presumably yielding new functions.

Different tests about selection in the human genome need to be done because many signals given by the $d_{N} / d_{S}$ ratio are likely to be false positives (Kelley et al. 2006; Akey 2009; Nei et al. 2010). In the present work, we also used LD analysis to detect selective sweeps, as described by Depaulis \& Veuille (1998), Kelly (1997), Kim \& Nielsen (2004), and Jacobs et al. (2016). We found an LD pattern that seemed to be a selection sweep candidate for various regions that could surround the fixation sites of selected alleles in $A S P M$ and MCPH1 within the phylogeny of Homo (Figures 4, 5). Similar results have been observed in other loci (Tishkoff et al. 1996).

Our results indicate positive selection at some sites of the ASPM and MCPHI genes in 
hominins, other hominids, and Simiiformes in general. Selection in the Homininae was especially evident in the ASPM exon 3, although sites under positive selection were reduced when one platyrrhine was included in the phylogeny. This could indicate adaptive evolution of the ASPM gene in the Platyrrhini as well, although more extensive taxon sampling is needed to clarify this issue. The general trend of cranial volume increase in hominins appears more related to increased molecular rates involved in non-synonymous changes in the ASPM phylogeny, suggesting strong positive selection on this gene during the evolution of Homo. The role of the ASPM gene in primate brain evolution-with special regard to encephalization - has been studied by Bond et al. (2002), Zhang (2003), Evans et al. (2004) Ali \& Meier (2008), and Montgomery \& Mundi (2010). Xu et al. (2012) extended such investigations to include cetaceans, which also exhibit a high degree of encephalization (Jerison 1973) as well as cognitive capacities and socialization (Marino 2002; Würsig 2002).

We detected some variations at exons 8 and 11 of $\mathrm{MCPH} 1$ that also showed positive selection in the species studied herein. Wang \& Su (2004) and Wang et al. (2008) detected positive selection in the $M C P H 1$ gene in a large Han Chinese sample, and Evans et al. (2005) demonstrated that $M C P H 1$ has evolved under strong positive selection among the Catarrhini, indicating a role of $M C P H 1$ in brain expansion throughout the evolution of several lineages in this taxon.

Previous studies have indicated that human cranial volume is associated with memory, perceptive organization, and processing speed, which are highly inheritable (Posthuma et al. 2003; McDaniel 2005). The association between the molecular evolution of microcephaly-related genes and the size of the neonatal brain is more evident in the neocortex rather than in the brain as a whole. A similar association has been observed between testicular size and the ASPM and CDK5RAP2 genes, but not the MCPHI and CENPJ genes. Positive selection acting on ASPM and CDK5RAP2 among Simiiformes has been established (Montgomery et al. 2011) together with the observation that transgenic mice harboring mutant ASPM have microcephaly and massive loss of germ cells; this affects cell differentiation during neurogenesis, and reduces brain size (Pulvers et al. 2010).

Modern human haplotype conformation in the MCPH1 gene may be the result of an introgression event from an archaic hominin group. This genetic exchange may have taken place approximately 37000 years ago, probably as a consequence of sexual interaction between two different hominin species (Evans et al. 2006). Because the chronology of the admixture event is roughly synchronic with the dispersal of modern $H$. sapiens throughout Europe, Evans et al. (2005) have suggested that the second species involved could have been $H$. neanderthalensis. This hypothesis is supported by the greater prevalence of $\mathrm{MCPHI}$ haplotype D outside sub-Saharan Africa. Such genetic evidence not only supports the possibility of admixture between modern humans and archaic Homo, such as Neanderthals, but also the idea that the evolution of modern humans could had the contribution of adaptive alleles from other human species. Paixão-Côrtes et al. (2012) compared the complete genomes of the chimpanzee, the Neanderthal reference genome, the Denisovan individual, and $H$. sapiens, focusing on the non-synonymous mutations of several genes and classifying the changes according to the degree of their effect. These authors confirmed positive selection in $A S P M$ and MCPHI among the hominins and indicated that interbreeding between early $H$. sapiens and other Homo species-such as the Neanderthals, Denisovans, and $H$. heidelbergensis - can explain in part the sharing of important cultural and behavioral developments according to archaeological evidence. Ancient cultural and genetic admixture between different human species likely contributed to neurological and behavioral diversity among modern humans (Ko 2016).

The evolution of brain size in humans leaded to the symbolization, articulated language, and complex reasoning - with integrated behavioral models - required for planning and creating complex tools, as well as complex social structures (Deacon 1997; Wong 2006). All of these characteristics also require highly elaborate neuronal organization. Future studies of ancient DNA could target other Homo species such as Homo floresiensis, H. erectus, and $H$. heidelbergensis, which have cranial volumes significantly lower than those of $H$. neanderthalensis and $H$. sapiens. Further research is required also to determine the extent of genetic, phenotypic, and cultural evolution, and its reticulation among archaic and modern humans.

The increase leap in the size of the encephalon and of neuronal complexity in $H$. habilis, which took place two MY ago, had profound consequences for the subsequent evolution of humans. Biological changes-such as enlarged 
body size, extended life cycle, increased brain size, number of neurons, size of neurons, number of glial cells, and number and size of neural connections that establish complex functions - and their genetic basis have been determinant in the staggering development of cognition and diversification of culture in humans.

\section{Acknowledgments}

We thank the facilities and support provided by Laboratorio de Antropología Genética at Instituto de Investigaciones AntropológicasUniversidad Nacional Autónoma de México, and Escuela Nacional de Antropología e Historia. We also thank the dedicated and knowledgeful edition by K. Paul. This work was supported by program PAPIIT-UNAM through project IN402818.

\section{Declaration of interest statement}

The authors have no conflicts of interest to declare.

\section{Data availability statement}

Sources for the genetic sequences as well as data and sources for brain size and metabolic rates are provided in the Supplementary Tables $\mathrm{S} 1$ and $\mathrm{S} 2$.

\section{References}

Akey JM. 2009. Constructing genomic maps of positive selection in humans: Where do we go from here? Genome Res. 19(5), 711-722. htps://doi.org/10.1101/gr.086652.108

Ali F, Meier R. 2008. Positive selection in $A S P M$ is correlated with cerebral cortex evolution across primates but not with whole-brain size. Mol. Biol. Evol. 25(11), 2247-2250. https://doi.org/10.1093/molbev/msn18 $\underline{4}$

Allman J, McLaughlin T, Hakeem A. 1993. Brain weight and life-span in primate species. Proc. Natl. Acad. Sci. USA 90(1):118-122.

https://doi.org/10.1073/pnas.90.1.118

Anisimova M, Bielawski JP, Yang Z. 2001. Accuracy and power of the likelihood ratio test in detecting adaptive molecular evolution. Mol. Biol. Evol. 18(8):1585-1592.

https://doi.org/10.1093/oxfordjournals .molbev.a003945

Arroyo M, Kuriyama R, Trimborn M, Keifenheim D, Cañuelo A, Sánchez A. 2017. $M C P H 1$, mutated in primary microcephaly, is required for efficient chromosome alignment during mitosis. Sci. Rep. 7:13019. https://doi.org/10.1038/s41598-01712793-7

Auton A, Abecasis GR, Altshuler DM, Durbin RM, Bentley DR, Chakravarti A, Schloss JA. 2015. A global reference for human genetic variation. Nature 526(7571):68-74. https://doi.org/10.1038/nature15393

Bond J, Roberts E, Mochida GH, Hampshire DJ, Scott S, Askham JM, Springell K, Mahadevan M, Crow YJ, Markham $\mathrm{AF}$, et al. 2002. ASPM is a major determinant of cerebral cortical size. Nat. Genet. 32(2):316-320. https://doi.org/10.1038/ng995

Bond J, Woods CG. 2006. Cytoskeletal genes regulating brain size. Curr. Opin. Cell Biol. 18(1):95-101. https://doi.org/10.1016/j.ceb.2005.11. $\underline{004}$

Borries C, Koenig A, Winkler P. 2001. Variation of life history traits and mating patterns in female langur monkeys (Semnopithecus entellus). Behav. Ecol. Sociobiol. 50(5), 391402.

https://doi.org/10.1007/s00265010039 $\underline{1}$

Bush GL, Case SM, Wilson AC, Patton JL. 1977. Rapid speciation and chromosomal evolution in mammals. Proc. Natl. Acad. Sci. USA 74(9), 3942-3946. https://doi.org/10.1073/pnas.74.9.394 2

Charlesworth B. 2009. Effective population size and patterns of molecular evolution and variation. Nat. Rev. Genet. 10(3):195-205. https://doi.org/10.1038/nrg2526

Deacon TW. 1997. The symbolic species: the co-evolution of language and the brain. New York (NY): W.W. Norton \& Co.

Delson E. 1992. Evolution of old word monkeys. In: Jones JS, Martin RD, Pilbeam D, Bunney S, editors. The Cambridge Encyclopedia of Human Evolution. Cambridge (UK): Cambridge University Press; p. 217222.

Depaulis F, Veuille M. 1998. Neutrality tests based on the distribution of haplotypes under an infinite-site model. Mol. Biol. Evol. 15(12):17881790.

https://doi.org/10.1093/oxfordjournals .molbev.a025905 
Desir J, Cassart M, David P, Van Bogaert P, Abramowicz M. 2008. Primary microcephaly with ASPM mutation shows simplified cortical gyration with antero-posterior gradient preand post-natally. Am. J. Med. Genet. Part A 146A:1439-1443. https://doi.org/10.1002/ajmg.a.32312

Dorus S, Vallender EJ, Evans PD, Anderson JR, Gilbert S, Mahowald M, Lahn BT. 2004. Accelerated Evolution of Nervous System Genes in the Origin of Homo sapiens. Cell 119(7):10271040.

https://doi.org/10.1016/j.cell.2004.11. $\underline{040}$

Evans PD, Anderson JR, Vallender EJ, Gilbert SL, Malcolm CM, Dorus S, Lahn BT. 2004. Adaptive evolution of ASPM, a major determinant of cerebral cortical size in humans. Hum. Mol. Genet. 13(5):489-494. https://doi.org/10.1093/hmg/ddh055

Evans PD, Gilbert SL, Mekel-Bobrov N, Vallender EJ, Anderson JR, VaezAzizi LM, Tishkoff SA, Hudson RR, Lahn BT. 2005. Microcephalin, a gene regulating brain size, continues to evolve adaptively in humans. Science 309(5741):1717-1720. https://doi.org/10.1126/science.11137 22

Evans PD, Mekel-bobrov N, Vallender EJ, Hudson RR, Lahn BT. 2006. Evidence that the adaptive allele of the brain size gene microcephalin introgressed into Homo sapiens from an archaic Homo lineage. Proc. Natl. Acad. Sci. USA 103(48):1817818183.

https://doi.org/10.1073/pnas.0606966 103

Falk D. 1983. Cerebral Cortices of East African Early Hominids. Science 221(4615):1072-1074.

Fish JL, Kosodo Y, Enard W, Pääbo S, Huttner WB. 2006. Aspm specifically maintains symmetric proliferative divisions of neuroepithelial cells. Proc. Natl. Acad. Sci. USA 103(27):10438-10443.

https://doi.org/10.1073/pnas.0604066 $\underline{103}$

Gaskin DE. 1982. The ecology of whales and dolphins. London: Heineman.

Godfrey LR, Samonds KE, Jungers WL, Sutherland MR. 2001. Teeth, Brains, and Primate Life Histories. Am. J. Phys. Anthropol. 114:192-214. https://doi.org/10.1002/1096-
8644(200103)114:3\%3C192::AIDAJPA1020\%3E3.0.CO;2-Q

Green RE, Krause J, Briggs AW, Maricic T, Stenzel U, Kircher M, Patterson N, Li H, Zhai W, Fritz MHY, et al. 2010. A draft sequence of the Neandertal genome. Science 328(5979):710-722. https://doi.org/10.1126/science. 11880 $\underline{21}$

Hajdinjak M, Fu Q, Hübner A, Petr M, Mafessoni F, Grote S, Skoglund P, Narasimham V, Rougier H, Crevecoeur I, et al. 2018. Reconstructing the genetic history of late Neanderthals. Nature 555:652656.

https://doi.org/10.1038/nature26151

Hartwig W, Rosenberger AI, Norconk MA, Owl MY. 2011. Relative Brain Size, Gut Size, and Evolution in New World Monkeys. Anat. Rec. 294:2207-2221. https://doi.org/10.1002/ar.21515

Haygood R, Fedrigo O, Hanson B, Yokoyama K, Wray GA. 2007. Promoter regions of many neural- and nutrition-related genes have experienced positive selection during human evolution. Nat. Genet. 39(9):1140-1144. https://doi.org/10.1038/npre.2007.69. 1

Hoekstra HE, Coyne J. 2007. The locus of evolution: Evo Devo and the genetics of adaptation. Evolution 61(5): 9951016. https://doi.org/10.1111/j.15585646.2007.00105.x

Holloway RL, Clarke RJ, Tobias PV. 2004. Posterior lunate sulcus in Australopithecus africanus: was Dart right? Hum. Palaeontol. Prehist. 3:287-293. https://doi.org/10.1016/j.crpv.2003.09 .030

Huelsenbeck JP, Ronquist F. 2001. MRBAYES: Bayesian inference of phylogeny. Bioinformatics 17:754755.

Isler K, Kirk EC, Miller JMA, Albrecht GA, Gelvin BR Martin RD 2008. Endocranial volumes of primate species: Scaling analyses using a comprehensive and reliable dataset. $\mathrm{J}$. Hum. Evol. 55(6): 967-987. https://doi.org/10.1016/j.jhevol.2008. 08.004

Jackson A, Eastwood H, Bell S, Adu J, Toomes C, Carr I, Roberts E, Hampshire D, Crow Y, Mighell A, et al. 2002 Identification of microcephalin, a protein implicated in 
determining the size of the human brain. Am. J. Hum. Genet. 71:136142. https://doi.org/10.1086/341283

Jacobs GS, Sluckin TJ, Kivisild T. 2016. Refining the use of linkage disequilibrium as a robust signature of selective sweeps. Genetics 203(4):1807-1825.

https://doi.org/10.1093/genetics/203.4 .NP

Jerison HJ. 1973. Evolution of the brain and intelligence. New York (NY): Academic Press.

Jones JS, Martin RD, Pilbeam D, Bunney S, editors. The Cambridge Encyclopedia of Human Evolution. Cambridge (UK): Cambridge University Press.

Kelley JL, Madeoy J, Calhoun JC, Swanson W, Akey JM. 2006. Genomic signatures of positive selection in humans and the limits of outlier approaches. Genome Res. 16(8):980989.

https://doi.org/10.1101/gr.5157306

Kelly JK. 1997. A test of neutrality based on interlocus associations. Genetics 146(3):1197-1206.

Kim Y, Nielsen R. 2004. Linkage disequilibrium as a signature of selective sweeps. Genetics 167(3):1513-1524.

https://doi.org/10.1534/genetics.103.0 25387

Ko KH. 2016. Hominin interbreeding and the evolution of human variation. J. Biol. Res.-Thessaloniki 23(1):17. https://doi.org/10.1186/s40709-0160054-7

Kouprina N, Pavlicek A, Mochida GH, Solomon G, Gersch W, Yoon YH, Collura R, Ruvolo M, Barrett JC, Woods CG, et al. 2004. Accelerated evolution of the ASPM gene controlling brain size begins prior to human brain expansion. PLoS Biology, 2(5), 653-663. 2004. https://doi.org/10.1371/journal.pbio.0 $\underline{020126}$

Kronenberg ZN, Fiddes IT, Gordon D, Murali $\mathrm{S}$, Cantsilieris S, Meyerson OS, Underwood JG, Nelson BJ, Chaisson MJP, Dougherty ML, et al. 2018. High-resolution comparative analysis of great ape genomes. Science 360(1085): eaar6343. https://doi.org/10.1126/science.aar634 $\underline{3}$

Larkin MA, Blackshields G, Brown NP, Chenna R, McGettigan PA, McWilliam H, Valentin F, Wallace
IM, Wilm A, Lopez R, et al. 2007. Clustal W and Clustal X version 2.0. Bioinformatics 23(21):2947-2948. https://doi.org/10.1093/bioinformatics /btm404

LeMaho Y, Goffart M, Rochas A, Felbabel H, Chatonnet J. 1981. Thermoregulation in the only nocturnal simian: the night monkey Aotus trivirgatus. Am. J. Physiol. 240(3):R156-R165. https://doi.org/10.1152/ajpregu.1981.2 40.3.R156

Leyva Hernández S. 2016. Genes implicados en la determinación del volumen cerebral en el linaje humano [bachelor's tesis]. Ciudad de México: Escuela Nacional de Antropología e Historia.

Lieberman D. 2011 The evolution of the human head. Cambridge (MA): Belknap Press of Harvard University Press.

Lin S, Rai R, Li K, Xu Z, Elledge SJ. 2005. BRIT1/MCPH1 is a DNA damage responsive protein that regulates the Brcal-Chkl pathway, implicating checkpoint dysfunction in microcephaly. Proc. Natl. Acad. Sci. USA 102(42):15105-15109. https://doi.org/10.1073/pnas.0507722 $\underline{102}$

Maddison DR, Maddison WP. 2003. MacClade 4. ver. 4.06. Sunderland (MA): Sinauer.

Marino L. 2002. Brain size evolution. In: Perrin WF, Würsig B, Thewissen JGM, editors. Encyclopedia of marine mammals. San Diego (CA): Academic Press; p. 158-162.

Martin RD. 1996. Scaling of the mammalian brain: the maternal energy hypothesis. News Physiol. Sci. 11:149-156. https://doi.org/10.1152/physiologyonli ne.1996.11.4.149

Martin DP, Lemey P, Lott M, Moulton V, Posada D, Lefeuvre P. 2010. RDP3: a flexible and fast computer program for analyzing recombination. Bioinformatics 26(19):2462-2463. https://doi.org/10.1093/bioinformatics $\underline{\text { btq467 }}$

Martin DP, Murrell B, Golden M, Khoosal A, Muhire B. 2015. RDP4: Detection and analysis of recombination patterns in virus genomes. Virus Evol. 1(1):1-5. https://doi.org/10.1093/ve/vev003

Martin D, Rybicki E. 2000. RDP: Detection of recombination amongst aligned sequences. Bioinformatics 16(6):562563. 
https://doi.org/10.1093/bioinformatics 116.6 .562

McDaniel MA. 2005. Big-brained people are smarter: A meta-analysis of the relationship between in vivo brain volume and intelligence. Intelligence 33(4): 337-346. https://doi.org/10.1016/j.intell.2004.1 $\underline{1.005}$

McHenry HM 1994. Tempo and mode in human evolution. Proc. Natl. Acad. Sci. USA 91(15):6780-6786.

Medrano González L. 2009. La evolución de los cetáceos. In: Morrone JJ, Magaña $\mathrm{P}$, editors. Evolución biológica. Una visión actualizada desde la revista Ciencias. Ciudad de México: Facultad de Ciencias, Universidad Nacional Autónoma de México; p. 539-588.

Meyer M, Kircher M, Gansauge MT,1 Li H, Racimo F, Mallick S, Schraiber JG, Jay F, Prüfer K, Filippo C, et al. 2012. A High-Coverage Genome Sequence from an Archaic Denisovan Individual. Science, 222(2012):1-14. https://doi.org/10.1126/science.12243 $\underline{44}$

Miyashita N Langley CH. 1988. Molecular and Phenotypic Variation of the white Locus Region in Drosophila melanogaster. Genetics 120:199-212.

Montgomery SH, Capellini I, Venditti C, Barton RA, Mundy NI. 2011. Adaptive evolution of four microcephaly genes and the evolution of brain size in anthropoid primates. Mol. Biol. Evol. 28(1):625-638. https://doi.org/10.1093/molbev/msq23 7

Montgomery SH, Mundy NI. 2010. Brain evolution: Microcephaly genes weigh in. Curr. Biol. 20(5):R244-R246. https://doi.org/10.1016/j.cub.2010.01. $\underline{043}$

Muthukrishna M, Doebeli M, Chudek M, Henrich J. 2018. The Cultural Brain Hypothesis: How culture drives brain expansion, sociality, and life history. PLoS Comput. Biol. 14(11): 1-37. https://doi.org/10.1371/journal.pcbi.1 006504

Nei M, Suzuki Y, Nozawa M. 2010. The neutral theory of molecular evolution in the genomic era. Annu. Rev. Genom. Hum. G. 11(1):265-289. https://doi.org/10.1146/annurevgenom-082908-150129

Neubauer S, Hublin J. 2012. The evolution of human brain development. Evol. Biol. 39:568-586.
Neubauer S, Hublin JJ, Gunz P. 2018. The evolution of modern human brain shape. Sci. Adv. 4(1): eaao5961. https://doi.org/10.1126/sciadv.aao596 $\underline{1}$

Padidam M, Sawyer S, Fauquet CM. 1999. Possible emergence of new geminiviruses by frequent recombination. Virology 265(2):218225. https://doi.org/10.1006/viro.1999.005 $\underline{6}$

Page SL, Chiu C, Goodman M. 1999. Molecular Phylogeny of Old World Monkeys (Cercopithecidae) as Inferred from $\gamma$-Globin DNA Sequences. Mol. Phyl. Evol. 13(2):348-359. https://doi.org/10.1006/mpev.1999.06 53

Paixão-Côrtes VR, Viscardi LH, Salzano FM, Hünemeier T, Bortolini MC. 2012. Homo sapiens, Homo neanderthalensis and the Denisova specimen: New insights on their evolutionary histories using wholegenome comparisons. Genet. Mol. Biol. 35(4 supl.1):904-911. https://doi.org/10.1590/S1415$\underline{47572012000600003}$

Passemard S, Verloes A, de Villemeur TB, Boespflug-Tanguy O, Hernandez $\mathrm{K}$, Laurent $\mathrm{M}$, Isidor $\mathrm{B}$, Alberti $\mathrm{C}$, Pouvreau N, Drunat S, et al. 2016. Abnormal spindle-like microcephalyassociated (ASPM) mutations strongly disrupt neocortical structure but spare the hippocampus and long-term memory. Cortex 74:158-176. https://doi.org/10.1016/j.cortex.2015. $\underline{10.010}$

Pennings PS, Hermisson J. 2006. Soft sweeps III: The signature of positive selection from recurrent mutation. PLoS Genet. 2(12):

e186. https://doi.org/10.1371/journal.pgen.0 020186

Perelman P, Johnson WE, Roos C, Seuánez HN, Horvath JE, Moreira MAM, Kessing B, Pontius J, Roelke M, Rumpler Y, Schneider MPC, Silva A, O’Brien SJ, Pecon-Slattery J. 2011. A Molecular Phylogeny of Living Primates. PLoS Genet. 7(3): e1001342. https://doi.org/10.1371/journal.pgen.1 001342

Pettersen EF, Goddard TD, Huang CC, Couch GS, Greenblatt DM, Meng EC, Ferrin TE. 2004. UCSF Chimera--a 
visualization system for exploratory research and analysis. J. Comput. Chem. 25(13):1605-1612. https://doi.org/10.1002/jcc.20084

Ponting C, Jackson AP. 2005. Evolution of primary microcephaly genes and the enlargement of primate brains. Science 14(3):241-248. https://doi.org/10.1016/j.gde.2005.04. $\underline{009}$

Pontzer $\frac{\mathrm{H}}{\mathrm{H}}$, Raichlen AC, Gordon AD, Schroepfer-Walker KK, Hare B, O’Neill MC, Muldoon KM, Dunsworth HM, Wood BM, Isler K, et al. 2014. Primate energy expenditure and life history. Proc. Natl. Acad. Sci. USA 111(4):14331437.

https://doi.org/10.1073/pnas.1316940 $\underline{111}$

Posthuma D, Baaré WFC, Pol HEH, Kahn RS, Boomsma DI, De Geus EJC. 2003. Genetic Correlations Between Brain Volumes and the WAIS-III Dimensions of Verbal Comprehension, Working Memory, Perceptual Organization, and Processing Speed. Twin Res. 6(2):131-139.

https://doi.org/10.1375/twin.6.2.131

Prüfer K, de Filippo C, Grote S, Mafessoni F, Korlevi P, Hajdinjak M, Vernot B, Skov L, Hsieh P, Peyrégne S, et al. 2017. A high-coverage Neandertal genome from Vindija Cave in Croatia. Science 358(6363):655-658. https://doi.org/10.1126/science.aao18 87

Prüfer K, Racimo F, Patterson N, Jay $F$, Sankararaman S, Sawyer S, Heinze A, Renaud G, Sudmant PH, de Filippo C, et al. 2014. The complete genome sequence of a Neanderthal from the Altai Mountains. Nature, 505(7481):43-49. https://doi.org/10.1038/nature12886

Pulvers JN, Bryk J, Fish JL, WilschBräuninger $\mathrm{M}$, Arai $\mathrm{Y}$, Schreier $\mathrm{D}$, Naumann R, Helppi J, Habermann B, Vogt J, et al. 2010. Mutations in mouse ASPM (abnormal spindle-like microcephaly associated) cause not only microcephaly but also major defects in the germline. Proc. Natl. Acad. Sci. USA 107(38):1659516600.

https://doi.org/10.1073/pnas.1010494 107

Ramos-Onsins SE, Rozas J. 2001. Statistical Properties of New Neutrality Tests
Against Population Growth. Mol. Biol. Evol. 19(12):2092-2100. https://doi.org/10.1093/oxfordjournals .molbev.a004034

Rightmire GP. 1998. Human evolution in the Middle Pleistocene: the role of Homo heidelbergensis. Evol. Anthropol. 6(6):218-227.

https://doi.org/10.1002/(SICI)15206505(1998)6:6\%3C218::AIDEVAN4\%3E3.0.CO;2-6

Rightmire GP. 2004. Brain size and encephalization in early to midPleistocene Homo. Am. J. Phys. Anthropol. 124(2):109-123. https://doi.org/10.1002/ajpa.10346

Robson SL, Wood B. 2008. Hominin life history: reconstruction and evolution. J. Anat. 212(4):394-425. https://doi.org/10.1111/j.14697580.2008.00867.x

Ross C. 1992. Basal Metabolic Rate, Body Weight and Diet in Primates: An Evaluation of the Evidence. Folia Primatol. 58(1):7-23. https://doi.org/10.1159/000156602

Roth G, Dicke U. 2012. Evolution of the brain and intelligence in primates. In: Hofman MA, Falk D, editors. Prog. Brain Res. 195:413-30.

Rozas J, Gullaud M, Blandin G, Aguadé M. 2001. DNA variation at the rp49 gene region of Drosophila simulans: evolutionary inferences from an unusual haplotype structure. Genetics 158(3):1147-1155.

https://doi.org/10.1093/genetics/158.3 .1147

Rozas J, Rozas R. 1999. DnaSP version 3: An integrated program for molecular population genetics and molecular evolution analysis. Bioinformatics 15(2): $\quad$ 174-175. https://doi.org/10.1093/bioinformatics 115.2 .174

Salminen MO, Carr JK, Burke DS, McCutchan FE. 1995. Identification of breakpoints in intergenotypic recombinants of HIV type 1 by bootscanning. AIDS Res. Hum. Retroviruses 11(11):1423-1425. https://doi.org/10.1089/aid.1995.11.14 $\underline{23}$

Sayers K. 2013. On folivory, competition, and intelligence: generalism, overgeneralizations, and models of primate evolution. Primates 54(2):111-124. https://dx.doi.org/10.1007\%2Fs10329 $\underline{-012-0335-1}$ 
Scally A, Dutheil JY, Hillier LW, Jordan GE, Goodhead I, Herrero J, Hobolth A, Lappalainen T, Mailund T, MarquesBonet T, et al. 2012. Insights into hominid evolution from the gorilla genome sequence. Nature 483(7388), 169-175.

https://doi.org/10.1038/nature10842

Schoenemann PT. 2006. Evolution of the size and functional areas of the human brain. Annu. Rev. Anthropol. 35(1):379-406.

https://doi.org/10.1146/annurev.anthr o.35.081705.123210

Shimodaira H, Hasegawa M. 2001. CONSEL: for assessing the confidence of phylogenetic tree selection. Bioinformatics 17(12):1246-1247. https://doi.org/10.1093/bioinformatics /17.12.1246

Sikora M, Seguin-Orlando A, Sousa VC, Albrechtsen A, Korneliussen T, Ko A, Rasmussen S, Dupanloup I, Nigst PR, Bosch MD, et al. 2017. Ancient genomes show social and reproductive behavior of early Upper Paleolithic foragers. Science 358(6363):659-662.

https://doi.org/10.1126/science.aao18 $\underline{07}$

Simons $\overline{E L}$, Seiffert ER, Ryan TM, Attia Y. 2007. A remarkable female cranium of the early Oligocene anthropoid Aegyptopithecus zeuxis (Catarrhini, Propliopithecidae). Proc. Natl. Acad. Sci. USA 104(21):8731-8736. https://doi.org/10.1073/pnas.0703129 104

Slatkin M. 2008. Linkage disequilibrium understanding the evolutionary past and mapping the medical future. Nat. Rev. Genet. 9(6):477-485. https://doi.org/10.1038/nrg2361

Snodgrass JJ, Leonard WR, Robertson ML. 2009. The Energetics of Encephalization in Early Hominids. In: Hublin JJ, Richards MP, editors. The Evolution of Hominin Diets. Integrating Approaches to the Study of Palaeolithic Subsistence. Dordrecht: Springer; p. 15-29.

Somel M, Franz H, Yan Z, Lorenc A, Guo S, Giger T, Kelso J, Nickel B, Dannemann M, Bahn S, et al. 2009. Transcriptional neoteny in the human brain. Proc. Natl. Acad. Sci. USA 106(14):5743-5748.

https://doi.org/10.1073/pnas.0900544 106
Thornton GK, Woods CG. 2009 Primary microcephaly: do all roads lead to Rome? TIG 25(11):501-510. https://doi.org/10.1016/j.tig.2009.09.0 $\underline{11}$

Tishkoff SA, Dietzsch E, Speed W, Pakstis AJ, Kidd JR, Cheung K, Bonné-Tamir B, Santachiara-Benerecetti AS, Moral P, Krings M, et al. 1996. Global patterns of linkage disequilibrium at the CD4 locus and modern human origins. Science 271(5254):1380-1387. https://doi.org/10.1126/science.271.52 $\underline{54.1380}$

Walker A, Shipman P. 2005. The Ape in the Tree. An Intellectual and Natural History of Proconsul. Cambridge (MA): Belknap Press of Harvard University Press.

Wang J, Li Y, Su B. 2008. A common SNP of $M C P H 1$ is associated with cranial volume variation in Chinese population. Hum. Mol. Genet. 17(9):1329-1335. https://doi.org/10.1093/hmg/ddn021

Wang YQ, Su B. 2004. Molecular evolution of microcephalin, a gene determining human brain size. Hum. Mol. Genet. 13(11):1131-1137. https://doi.org/10.1093/hmg/ddh127

Ward CV, Flinn M, Begun DR. 2004. Body size and intelligence in hominoid evolution. In: Russon AE, Begun DR, editors. The Evolution of Thought. Evolutionary Origins of Great Ape Intelligence. Cambridge (UK): Cambridge University Press; p. 335349.

Wilson AC, Bush GL, Case SM, King MC. 1975. Social structuring of mammalian populations and rate of chromosomal evolution. Proc. Natl. Acad. Sci. USA 72(12):5061-5065. https://doi.org/10.1073/pnas.72.12.50 $\underline{61}$

Wong K. 2006. The morning of the modern mind. Sci. Am. 16(2):74-83. https://doi.org/10.1038/scientificameri can0605-86

Woolfit M. 2009. Effective population size and the rate and pattern of nucleotide substitutions. Biol. Lett. 5:417-420. https://doi.org/10.1098/rsbl.2009.0155

Würsig B. 2002. Intelligence and cognition. In: Perrin WF, Würsig B, Thewissen JGM, editors. Encyclopedia of marine mammals. San Diego (CA): Academic Press; p. 628-636.

Xing J, Wang H, Han K, Ray DA, Huang CH, Chemnick LG, Stewart CB, Disotell 
TR, Ryder OA, Batzer MA. 2005. A mobile element based phylogeny of Old World monkeys. Mol. Phyl. Evolution 37(3):872-880. https://doi.org/10.1016/j.ympev.2005. $\underline{04.015}$

Xu S, Chen Y, Cheng Y, Yang D, Zhou X, Xu J, Zhou K, Yang G. 2012. Positive selection at the ASPM gene coincides with brain size enlargements in cetaceans. Proc. Biol. Sci. B 279(1746):4433-4440.

https://doi.org/10.1098/rspb.2012.172 $\underline{9}$

$\mathrm{Xu}$ X, Lee J, Stern DF. 2004. Microcephalin is a DNA damage response protein involved in regulation of $C H K 1$ and BRCA1. J. Biol. Chem. 279(33):34091-34094. https://doi.org/10.1074/jbc.C4001392 $\underline{00}$

Yang Z. 2007 . PAML 4: Phylogenetic analysis by maximum likelihood. Mol. Biol.
Evol. 24(8):1586-1591. https://doi.org/10.1093/molbev/msm0 $\underline{88}$

Yang Z, Bielawski JP. 2000. Statistical methods for detecting molecular adaptation. TREE 15(12):496-503. https://doi.org/10.1016/S01695347(00)01994-7

Zhang J. 2003. Evolution of the human ASPM gene, a major determinant of brain size. Genetics 165(4):2063-2070. https://doi.org/10.1093/genetics/165.4 .2063

Zimin AV, Cornish AS, Maudhoo MD, Gibbs RM, Zhang X, Pandey S, Meehan DT, Wipfler K, Bosinger SE, Johnson ZP, et al. 2014. A new rhesus macaque assembly and annotation for nextgeneration sequencing analyses. Biol. Direct 9(1):20. https://doi.org/10.1186/1745-6150-9$\underline{20}$

Publisher's note: Eurasia Academic Publishing Group (EAPG) remains neutral with regard to jurisdictional claims in published maps and institutional affiliations.

Open Access This article is licensed under a Creative Commons Attribution-NoDerivatives 4.0 International (CC BY-ND 4.0) licence, which permits copy and redistribute the material in any medium or format for any purpose, even commercially. The licensor cannot revoke these freedoms as long as you follow the licence terms. Under the following terms you must give appropriate credit, provide a link to the license, and indicate if changes were made. You may do so in any reasonable manner, but not in any way that suggests the licensor endorsed you or your use. If you remix, transform, or build upon the material, you may not distribute the modified material.

To view a copy of this license, visit https://creativecommons.org/licenses/by-nd/4.0/. 